Accepted 27 July 2010.

Copyright (c) 2010 by Lippincott Williams \& Wilkins

ISSN 0041-1337/10/9009-1039

DOI: 10.1097/TP.0b013e3181f44cle

\section{REFERENCES}

1. Di Benedetto F, Di Sandro S, De Ruvo N, et al. First report on a series of HIV patients undergoing rapamycin monotherapy after liver transplantation. Transplantation 2010; 89: 733.

2. Ragni MV, Belle SH, Im K, et al. Survival of human immunodeficiency virus-infected liver transplant recipients. J Infect Dis 2003; 188: 1412.

3. Heredia A, Amoroso A, Davis C, et al. Rapamycin causes down-regulation of CCR 5 and accumulation of anti-HIV beta-chemokines: An approach to sup- press R5 strains of HIV-1. Proc Natl Acad Sci USA 2003; 100: 10411.
4. Gilliam BL, Heredia A, Devico A, et al. Rapamycin reduces CCR5 mRNA levels in macaques: Potential applications in HIV-1 prevention and treatment. AIDS 2007; 21: 2108

5. Moreno A, Bárcena R, Quereda C, et al. Safe use of raltegravir and sirolimus in an HIVinfected patient with renal impairment after orthotopic liver transplantation. AIDS 2008; 22: 547

\title{
Rapamycin and HIV Replication in Liver Transplant Recipients
}

We appreciate the concerns from Baccarani et al. regarding the active replication of HIV among our series of patients in calcineurin inhibitor immunosuppressive treatment after liver transplantation (LT). To better understand the experience of Baccarani et al., it would be necessary to have more detailed data, such as antiretroviral (ARV) therapy adopted, HIV viral load (VL) at different time points from transplantation to the last check, and HIV VL of all patients of their series. An important difference between our experience and the experience of Baccarani et al. seems to be the switch time from calcineurin inhibitor to rapamycin. Indeed, the median time of immunosuppression switch in the patient cohort of Baccarani et al. was significantly longer then in our experience.

HIV VL control is mandatory for the success of patient and organ survival postorthotopic liver transplantation, and this is a matter of the choice of the best ARV therapy available independently of the type of antirejection treatment. In this perspective, we also discourage LT in patients with no effective ARV option postLT. Never the less the questions "when" and "what to start" ARV post-LT are still open and our experience meant to underline that rapamycin ability to inhibit HIV replication needs to be considered while tailoring ARV post-LT.

In our series, most patients had undetectable HIV VL after transplantation; however, two patients developed HIV reactivation, although they were on a triple
ARV therapy. Instead, HIV replication did not occur among the rapamycin group. However, based on the experiences reported in the literature (1-5), nobody could know whether rapamycin is really effective in HIV replication control among liver transplant recipients. Since the study by Heredia et al. (4), our impression, from a preliminary analysis of a set of liver transplant HIV+ recipients, is that rapamycin may allow a better control of HIV replication. We hypothesized that rapamycin contributed to a more rapid ability to obtain VL undetectable in patients with VL rebound secondary to ARV interruption in the early postorthotopic liver transplantation period.

To definitively establish a baseline on this topic, a prospective study with a larger patient cohort and with more appropriate clinical tests (such as CCR 5 count on the lymphocyte surface) is necessary. We also believe that future studies may be able to specifically investigate the potential advantage of rapamycin in HIV VL kinetics, in reducing HIV residual viremia in patients with undetectable VL, and in the reduction of hepatitis $C$ virus recurrence.

\section{Fabrizio Di Benedetto Stefano Di Sandro ${ }^{1}$ Roberto Ballarin ${ }^{1}$ Giovanni Guaraldi ${ }^{2}$ Giorgio E. Gerunda ${ }^{1}$}

${ }^{1}$ Liver and Multivisceral Transplant Center University of Modena and Reggio Emilia Modena, Italy

\author{
${ }^{2}$ Department of Medicine and Medical \\ Specialties \\ Infectious Diseases Clinic \\ University of Modena and Reggio Emilia \\ Modena, Italy
}

Address correspondence to: Fabrizio Di Benedetto, M.D., Ph.D., Liver and Multivisceral Transplant Center, University of Modena and Reggio Emilia, Via del Pozzo 71, 41100 Modena, Italy.

E-mail: f.diben@virgilio.it

Received 19 July 2010

Accepted 4 August 2010.

Copyright () 2010 by Lippincott Williams \& Wilkins

ISSN 0041-1337/10/9009-1040

DOI: 10.1097/TP.0b013e3181f5c434

\section{REFERENCES}

1. Liu R, Paxton WA, Choe S, et al. Homozygous defect in HIV-1 coreceptor accounts for resistance of some multiply-exposed individuals to HIV-1 infection. Cell 1996; 86: 367.

2. Lin YL, Mettling C, Portales P, et al. Cell surface CCR5 density determines the postentry efficiency of R5 HIV-1 infection. Proc Natl Acad Sci USA 2002; 99: 15590.

3. Weissman D, Dybul M, Daucher MB, et al. Interleukin-2 up-regulates expression of the human immunodeficiency virus fusion coreceptor CCR 5 by $\mathrm{CD} 4^{+}$lymphocytes in vivo. J Infect Dis 2000; 181: 933.

4. Heredia A, Amoroso A, Davis C, et al. Rapamycin causes down-regulation of CCR5 and accumulation of anti-HIV betachemokines: An approach to suppress R5 strains of HIV-1. Proc Natl Acad Sci USA 2003; 100: 10411.

5. Samonakis DN, Cholongitas E, Triantos CK, et al. Sustained, spontaneous disappearance of serum HCV-RNA under immunosuppression after liver transplantation for $\mathrm{HCV}$ cirrhosis. J Hepatol 2005; 43: 1091.

\section{The Spleen as a Site for Hematopoiesis}

We read with interest the recent article by Tan and O'Neill in Transplantation (1). On the basis of a spleen transplant experiment in allotype-distinct recipient mice, they describe the role of this organ as a site for endogenous myelopoiesis. Although the role of the spleen as an extramedullary site of hematopoiesis is well established in this species, it has remained uncertain whether this can be extrapolated to humans. 